\title{
GPS Based Toll Collection System
}

\author{
S Aishwarya Rao ${ }^{1}$, Sahana $\mathrm{S}^{1}$, Priyanka N S ${ }^{1}$, Inchara $\mathrm{G}^{1}$, Rajashekar M B* \\ Department of CSE, GSSSIETW, Mysuru, Karnataka, India
}

DOI: https://doi.org/10.21467/proceedings.1.18

* Corresponding author email: rajashekar@gsss.edu.in

\begin{abstract}
Transportation has emerged as a dominant part of India. Toll plazas play a crucial role in maintaining the road transportation. At present, manual toll collection is most widely used collection method in India. It significantly requires a toll collector or attendant. Due to manual intervention, the processing time at toll plazas is highest. The project has been designed for the automation in toll tax payment using GPS and GSM Technology. Automation of toll plaza has been experimented using combination of Microcontroller, RFID, Global positioning system, Global system for Mobile. Implementation of automation in toll plaza enhances the monitoring of vehicles that are travelling in predestined routes. This project aims in designing a system, which automatically identifies the vehicle that advance towards the toll plazas and observes the vehicle number and the time of arrival. If matches exist between vehicle data and GPS data, then predetermined amount is automatically taken from the user account. It passes this information to avoid the Traffic congestion at toll plazas and helps in consuming less amount of fuel.
\end{abstract}

Index Terms- Toll Gate, Toll collection system, user, RFID Tag.

\section{INTRODUCTION}

Automation means to reduce the activities of human labor. This means the process handled by the humans will be carried out by the machines once it is programmed such a way that it reduces more amount of time and it decreases the possibility of risk factor. Overview of the toll booth system in late 90s is, around 90th century the toll plazas were controlled manually. Those system requires two people for opening and closing of the gate and another two are for reception of the money also data keeping etc. Later on, in the year of 1995 the development of Express Highway Systems introduced semi-automatic toll plazas were constructed in which data is stored in computers and operation of gate is automatic. Two persons are required for single toll plaza. Later on, the upcoming project aims in developing the human less toll plazas. The notable advantage of this technology is the opportunity to reduce the traffic congestion in toll plaza during festive seasons. Also, this is a method by which to control complaints from motorists relevant to the inconveniences associated with manually making payments at the 
tollbooths. Another obvious advantage, this method recognizes the benefit of the toll booth operators.

In this project the microcontroller will be placed in vehicle unit and also has a GPS receiver and GSM unit. When driver enters toll gate mp3 module will give voice information about private toll gate. The driver enters destination to be reached using key selection so the module in vehicle unit takes the present GPS location when vehicle starts (start point) and sends to android unit (toll collection unit) and the selected destination is also sent to android unit via GSM. The predetermined amount is deducted automatically from user account when he exit from the toll gate. Automatic Toll Collection lanes improve the speed and efficiency of traffic flow, save drivers time and also results of better flow, congestion is reduced, fuel economy is improved, and pollution is reduced.

\section{LITERATURE SURVEY}

\subsection{Electronic Toll Collection System Based on Global Positioning System Technology}

Currently, most electronic toll collection (ETC) systems around the world are implemented by DSRC (dedicated short range communication) technology. However global positioning system technique is applied to ETC in recent years. It is an innovative technology for Expressway Network electronic toll collection solution. In this paper, the frame composing and working flow of the system are described, the advantages and disadvantages of the system are discussed and the application of GPS-based ETC system in China is detailedly discussed at last.

\subsection{RFID Based Toll Collection system}

The automated toll collection system using passive Radio Frequency Identification (RFID) tag emerges as a convincing solution to the manual toll collection method employed at tollgates. Time and efficiency are a matter of priority of present day. In order to overcome the major issues of vehicle congestion and time consumption RFID technology is used. RFID reader fixed at tollgate frame (or even a hand-held reader at manual lane, in case RFID tagged vehicle enters manual toll paying lane) reads the tag attached to windshield of vehicle. The object detection sensor in the reader detects the approach of the incoming vehicle's tag and toll deduction take place through a prepaid card assigned to the concerned RFID tag that belongs to the owners' account.

\subsection{Computer Vision Based Vehicle Detection for Toll Collection System Using Embedded Linux}

Many highway toll collection systems have already been developed and are widely used in India. Some of these include Manual toll collection, RF tags, Barcodes, Number plate recognition. All these systems have disadvantages that lead to some errors in the corresponding system. This paper presents a brief review of toll collection systems present in India, their advantages and disadvantages and also aims to design and develop a new efficient

Proceedings of the $3^{\text {rd }}$ National Conference on Image Processing, Computing, Communication, Networking and Data Analytics (NCICCNDA 2018) 
toll collection system which will be a good low-cost alternative among all other systems. The system is based on Computer Vision vehicle detection using Open CV library in Embedded Linux platform. The system is designed using Embedded Linux development kit (Raspberry pi). In this system, a camera captures images of vehicles passing through toll booth thus a vehicle is detected through camera. Depending on the area occupied by the vehicle, classification of vehicles as light and heavy is done.

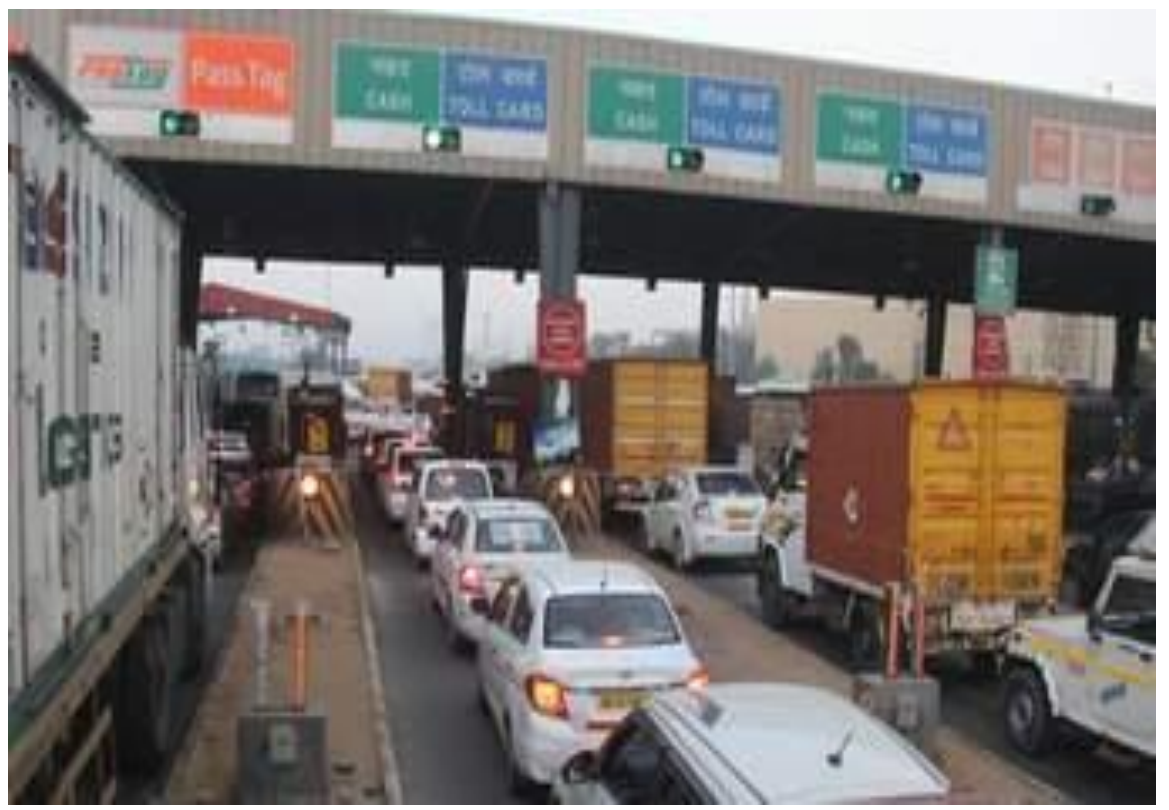

Figure 2.1.1 : Automated toll collection system

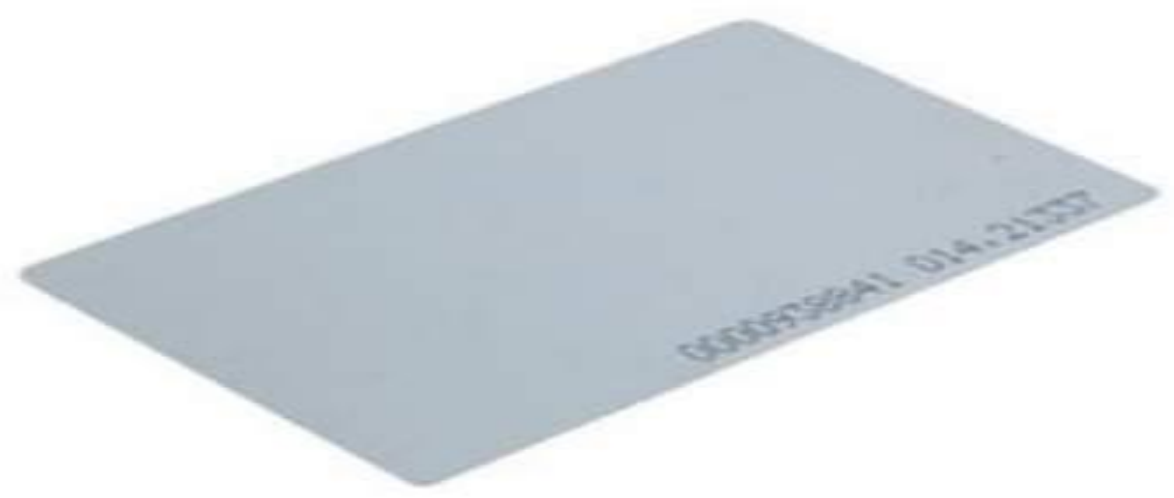

Figure 2.1.2 : RFID Tag 


\section{PROPOSED SYSTEM}

The functional concept of a manual toll system is simple: the motorist takes a ticket at the entrance to the motorway and presents it at the tollbooth at the exit. Ticketing and toll barriers can also be placed on each section of motorway. With technological progress, these systems have evolved towards electronic toll collection, allowing traffic to flow more smoothly and improving service to both users and operators. System consists of Automatic Toll Collection Centre, control gates and on-board units.

The system is based on an innovative combination of mobile telecommunications technology (GSM) and GPS, the satellite-based Global Positioning System. The main element of the automatic log-on system is the On-Board Unit (OBU). With the aid of GPS satellite signals and other positioning sensors, the OBU automatically determines how many kilo meters have already been driven on the toll route, calculates the toll based on the vehicle and toll rate information that has been entered, and transmits this information to the ATCS computer centre for further processing. Software will be support with electronic road maps and data of users registered in as well as data charges of highways and expressways. Charge counting will be started after highway entrance gate and finished after highway exit gate. Data on vehicle position will be additionally approved by GPS system and delivered to ATCC by GSM net. The toll amount is based on the truck's emission category and number of axles, as well as on the length of the toll route. GPS placed in the toll system gives the location information to the user. As the vehicle enters the toll gate ,RFID tad in the vehicle is read by RFID scanner placed in the toll gate. RDIF tag is linked with the users account. When RFID scanner reads the tag the amount is deducted from the users account and the notification is sent to the user through android application. Account information is updated in the database and in RFID card linked with the user.

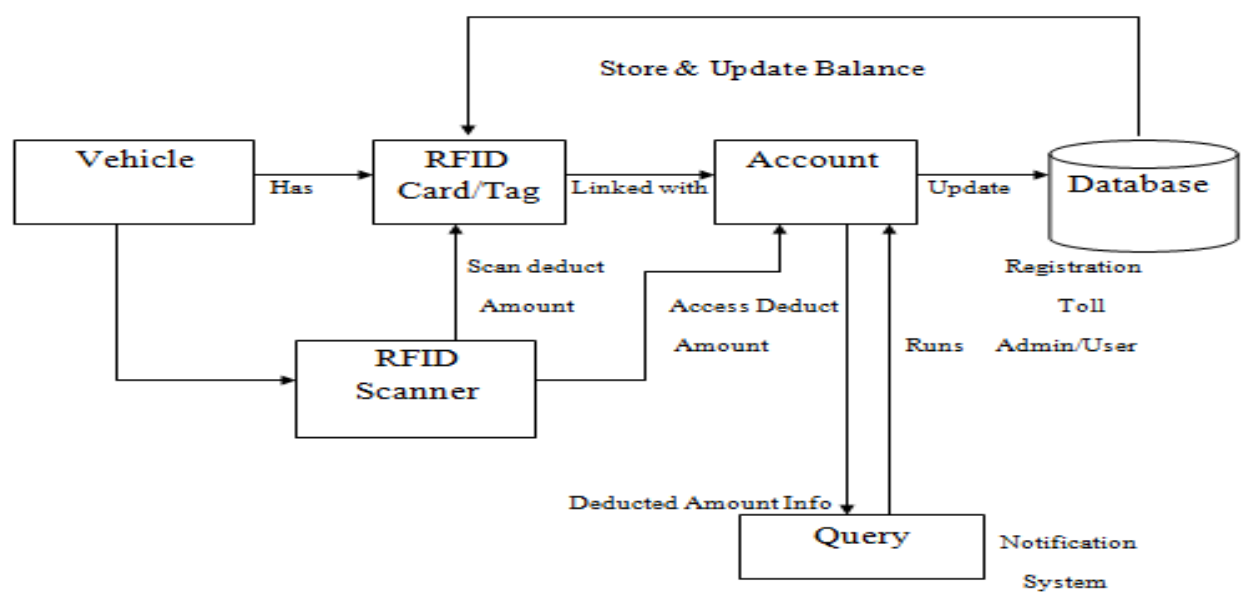

Figure 3.1: Workflow

Proceedings of the $3^{\text {rd }}$ National Conference on Image Processing, Computing, Communication, Networking and Data Analytics (NCICCNDA 2018) 
GPS Based Toll Collection System

\section{Advantages of Proposed system}

- This model reduces the activities of human labor.

- It reduces more amount of time and decreases the possibility of risk factor.

- The notable advantage of this technology is the opportunity to reduce the traffic congestion in toll plaza during festive seasons.

\section{CONCLUSIONS}

The above mentioned technologies are future electronic toll collect systems and have different attributes, pros and cons. For many years DSRC systems have been preferred, due to their simplicity of operation, need road side equipment typically mounted on a gantry, with electronic tags in the vehicles which may be read only, read write or smart card based. The proposed system based on a combination of mobile communication technology (GSM) and a satellite based global positioning system (GPS). An innovative log on unit OBU, which automatically calculate the amount of charge due and take in to account, depends on the type of the vehicle. It will also act like a platform for vehicle identification and prove effective in tracking stolen vehicles. With regard to future expansion and development, the satellite-based toll collection system will be a better solution, especially with regard to flexibility when it comes to extending toll collection to every road category and in terms of cost efficiency in an implementation operation.

\section{References}

[1] Gabriel Nowacki, Izabella Mitraszewska, Tomasz Kamiński, The National Automatic Toll Collection System For The Republic Of Poland, Transport And Telecommunication, 2008, Volume 9, No 2, 24-38

[2] Institute Of Transportation Studies Www.Calccit.Org/... Electronic_Toll_Collection / Electron _Toll_Collection

[3] New Electronic Toll Collection System By May 2012: Nath, Hindustan Times Fri Mar 16, New Delhi

[4] Dr. Khali Persad, Dr. C. Michael Walton, Shahrivar Hussain, Toll Collection Technology and bestPractices, Project 0-5217: Vehicle/License Plate Identification For Toll Collection Applications Aug 2006; Revised Jan 2007.

[5] Sans Institute Reading Room Http://Www.Sans.Org/Reading_Room/Whitepapers/Threats/Electr onic-TollCollection_1424

[6] Wikipedia: Electronic Toll Collection. Http://En.Wikipedia.Org/Wiki/Electronic_Tol

[7] Wikipedia: Road Pricing. Http://En.Wikipedia.Org/Wiki/Road_Pricing Accessed 02/06 